\title{
Treatment cost of metastatic colon cancer in Turkey
}

Guvenc Kockaya ${ }^{1}$, Mine Polat ${ }^{2}$, Albert I. Wertheimer ${ }^{3}$, Ahmet Özet ${ }^{4}$, Simten Malhan ${ }^{2}$, İsmail Mert Vural ${ }^{5}$, Akif Akbulat ${ }^{5}$, Guven Artıran ${ }^{5}$, Hakki Gürsöz ${ }^{5}$, Saim Kerman ${ }^{5}$

Health Economics and Policy Association, Ankara, Turkey

Baskent University, Ankara, Turkey

3 Temple University, Philadelphia, USA

4 Gazi University, Ankara, Turkey

5 Turkish Medicine and Medical Device Agency, Ankara, Turkey

\begin{abstract}
OBJECTIVES: Colon cancer is the third most common in the top cancer incidence list in Europe. In Europe 212,000 patients die every year due to colon cancer. In Turkey 120,000-130,000 new cancer patients are diagnosed every year, 7.1\% of whom are diagnosed to have developed colon cancer. Metastases will occur in up to $50 \%$ of the patients who are newly diagnosed. Survival appears to be further prolonged to more than 20 months with new pharmaceuticals; however, these new pharmaceuticals increase the total cost of care. The aim of this study is to estimate the cost implications of new colon cancer treatment options for Turkey.

METHODS: Gazi University Hospital treatment protocols for colon cancer treatment were used. Cost of FUFA (5 FU/LV), FOLFIRI, FOLFOX, bevacizumab/FUFA, bevacizumab/FOLFIRI, bevacizumab/FOLFOX, irinotecan and irinotecan/cetixumab protocols were calculated. The cost of combination of protocols were calculated depending on a Markov analysis. The exchange rate was US\$ 1 for TL 1.5.

RESULTS: Depending on the life expectancy the lowest total cost was established by FUVA (US $\$ 5,359$ ). It was followed by FOLFIRI then FOLFOX and FOLFOX, US\$14,144 and US\$16,553, respectively. The lowest cost for each week of life expectancy was established by FUVA with US\$ 98.

CONCLUSIONS: Only FUFA, FOLFIRI followed by FOLFIX, FOLFIRI/bevacizumab then FOLFOX then cetuximab, FOLFOX/bevacizumab then irinotecan then cetuximab/irinotecan and FOLFIRI/bevacizumab then FOLFOX then cetuximab/irinotecan were under the cost effectiveness curve. In addition no treatments ICER was under the WHO`s threshold for Turkey, except FOLFIRI then FOLFOX compared with FUVA.
\end{abstract}

\section{Keywords}

Oncology; Colon cancer; Cost-effectiveness

\section{INTRODUCTION}

Colon cancer was reported as the third most prevalent in the world with 940,000 new cases and 500,000 deaths each year [1,2]. It was reported that 142,570 men and women were diagnosed with colorectal cancer (CRC) and 57,000 men and women died in 2010 in US $[3,4]$. In Japan, colorectal cancer is the third leading cause of cancer death with 40,000 death per year $[5,6]$. In Turkey, incidence of cancer is 173,85 per $100,000,7,1 \%$ of whom are diagnosed to have developed colon cancer [7]. In addition to prevalence and great mortality numbers metastases will develop in $30-40 \%$ of CRC patients [8]. This metastasis rate can also cause mortality. In the light of these, it could be said that metastases will occur in 2-3,000 colon cancer patients every year in Turkey. Cost of treatment of CRC is also high. The National Institutes of Health estimated that direct medical costs including inpatient and outpatient care, drugs, and devices for colon cancer amounted to $\$ 14$ billion for the USA [9].

Treatments for metastatic colon cancer are mainly palliative and aim to increase the duration and the quality of the patient's remaining life [10]. For many years 5-fluorouracil (5-FU) was the only active agent which was associated with 12 month survival in colorectal cancer [10-12]. Several new active chemotherapy and monoclonal antibodies have been approved and implemented into routine clinical practice. Irinotecan, a
Corresponding author

Dr. Güvenç Koçkaya Bilim Sokak Sun Plaza K:2-3 Maslak 34398, Şişli-ïstanbul guvenckockaya@ yahoo.com

\section{Disclosure}

The authors have no financial competing interest to declare 
semi synthetic inhibitor of topoisomerase, and oxaliplatin, a third-generation platinum compound, were developed as salvage therapies for patients failing 5-FU $[10,13,14]$ and are treatment options for first-line, second-line and sequential treatment in colorectal cancer [10]. Many patients are now treated with sequential therapy resulting in prolonged overall survival to over 20 months $[10,15]$.
However, the cost associated with this improved survival may be very high, even in the United States [16]. Although there are many cost studies for CRC from different countries, there is not any cost study for Turkey where the government funded social security program covers approximately $85 \%$ of the population with Social Security Institution (SGK). It was reported that $€ 485$ million was spent for cancer treatment by SGK in year 2009

\begin{tabular}{|c|c|c|c|c|c|c|c|c|}
\hline \multirow[b]{2}{*}{ Protocol } & \multirow{2}{*}{ Pharmaceutical } & \multirow{2}{*}{ Administration } & \multicolumn{6}{|c|}{ Day } \\
\hline & & & 1 & 2 & 3 & 4 & 5 & 14 \\
\hline \multirow{2}{*}{$\begin{array}{l}\text { FUFA (5FU/LV) (1 amp } \\
\text { Metpamid, } 1 \text { amp Decort, } \\
1 \text { amp Systal and laboratories) }\end{array}$} & 5-Fluorouracil $\left(425 \mathrm{mg} / \mathrm{m}^{2}\right)$ & 15 min. infusion in 250 cc SS & + & + & + & + & + & \\
\hline & Folinic acid $\left(20 \mathrm{mg} / \mathrm{m}^{2}\right)$ & i.v. push & + & + & + & + & + & \\
\hline \multirow{4}{*}{$\begin{array}{l}\text { FOLFIRI } \\
\text { (tropisetron } 5 \text { mg or } \\
\text { ondansetron } 4-8 \text { mg, } 1 \text { amp } \\
\text { Decort + } 1 \text { amp Systral and } \\
\text { laboratories) }\end{array}$} & Irinotekan (180 mg/m²) & 90 min. infusion in 250 cc SS & + & & & & & \\
\hline & Folinic acid $(200$ mg/m²) & 2 hrs infusion in 250 cc SS & + & + & & & & \\
\hline & $5-\mathrm{FU}\left(400 \mathrm{mg} / \mathrm{m}^{2}\right)$ & 15 min. infusion in 250 cc SS & + & + & & & & \\
\hline & $5-\mathrm{FU}\left(600 \mathrm{mg} / \mathrm{m}^{2}\right)$ & 22 hrs infusion in 1000 cc SS & + & + & & & & \\
\hline \multirow{4}{*}{$\begin{array}{l}\text { FOLFOX (tropisetron } 5 \text { mg or } \\
\text { ondansetron } 4-8 \mathrm{mg}, 1 \text { amp } \\
\text { Dekort, } 1 \text { amp Systral) }\end{array}$} & Oxaliplatin $\left(85 \mathrm{mg} / \mathrm{m}^{2}\right)$ & $\begin{array}{l}2 \text { hrs infusion in } 1000 \text { cc \%5 } \\
\text { dextrose }\end{array}$ & + & & & & & \\
\hline & Folinic acid (200 mg/m²) & $\begin{array}{l}2 \text { hrs infusion in } 250 \text { cc } \% 5 \\
\text { dextrose }\end{array}$ & + & + & & & & \\
\hline & $5-\mathrm{FU}\left(400 \mathrm{mg} / \mathrm{m}^{2}\right)$ & 15 min. infusion in 250 cc SS & + & + & & & & \\
\hline & $5-\mathrm{FU}\left(600 \mathrm{mg} / \mathrm{m}^{2}\right)$ & 22 hrs İnfusion in 1000 cc SS & + & + & & & & \\
\hline \multirow{3}{*}{$\begin{array}{l}\text { Bevacizumab/FUFA ( } 1 \text { amp } \\
\text { Metpamid, } 1 \text { amp Dekort and } 1 \\
\text { amp Systral) }\end{array}$} & Bevacizumab (5 mg/kg) & in 100 cc SS & + & & & & & + \\
\hline & 5-Fluorouracil $\left(425 \mathrm{mg} / \mathrm{m}^{2}\right)$ & 15 min. infusion in 250 cc SS & + & + & + & + & + & \\
\hline & Folinic acid $\left(20 \mathrm{mg} / \mathrm{m}^{2}\right)$ & i.v. push & + & + & + & + & + & \\
\hline
\end{tabular}

Table I. Protocols of treatments 1 $\mathrm{SS}=$ saline solution

\begin{tabular}{|c|c|c|c|c|c|c|c|}
\hline \multirow{2}{*}{ Protocol } & \multirow{2}{*}{ Pharmaceutical } & \multirow{2}{*}{ Administration } & \multicolumn{5}{|c|}{ Day } \\
\hline & & & 1 & 8 & 15 & 22 & 29 \\
\hline \multirow{4}{*}{$\begin{array}{l}\text { Bevacizumab/FOLFIRI (tropisetron } \\
5 \mathrm{mg} \text { or ondansetron } 4-8 \mathrm{mg}, 1 \\
\text { amp Decort }+1 \text { amp Systral and } \\
\text { laboratories) }\end{array}$} & Irinotekan (125 mg/m²) & 90 min. infusion in 250 cc SS & + & + & + & + & \\
\hline & Folinic acid $(20$ mg/m²) & i.v. push & + & + & + & + & \\
\hline & 5-FU (500 mg/m²) & $15 \mathrm{~min}$. infusion in $250 \mathrm{cc}$ SS & + & + & + & + & \\
\hline & Bevacizumab (5 mg/kg) & in 100 cc SS & + & & + & & + \\
\hline \multirow{5}{*}{$\begin{array}{l}\text { Bevacizumab/FOLFOX (tropisetron } \\
5 \mathrm{mg} \text { or ondansetron } 4-8 \mathrm{mg}, 1 \mathrm{amp} \\
\text { Dekort, } 1 \text { amp Systral) }\end{array}$} & Bevacizumab (5 mg/kg) & in 100 cc SS & + & & & & + \\
\hline & Oxaliplatin $\left(85 \mathrm{mg} / \mathrm{m}^{2}\right)$ & $\begin{array}{l}2 \text { hrs infusion in } 1000 \mathrm{cc} \% 5 \\
\text { dextrose }\end{array}$ & + & & & & \\
\hline & Folinic acid $\left(200 \mathrm{mg} / \mathrm{m}^{2}\right)$ & $\begin{array}{l}2 \text { hrs infusion in } 250 \text { cc } \% 5 \\
\text { dextrose }\end{array}$ & + & + & & & \\
\hline & $5-\mathrm{FU}\left(400 \mathrm{mg} / \mathrm{m}^{2}\right)$ & 15 min. infusion in 250 cc SS & + & + & & & \\
\hline & $5-\mathrm{FU}\left(600 \mathrm{mg} / \mathrm{m}^{2}\right)$ & 22 hrs nfusion in 1000 cc SS & + & + & & & \\
\hline $\begin{array}{l}\text { Irinotecan (tropisetron } 5 \mathrm{mg} \text { or } \\
\text { ondansetron 4-8 mg, } 1 \text { amp Dekort, } 1 \\
\text { amp Systral) }\end{array}$ & $\left(350 \mathrm{mg} / \mathrm{m}^{2}\right)$ & 90 min infusion in 250 cc SS & + & & & & \\
\hline \multirow{2}{*}{$\begin{array}{l}\text { Irinotecan + Cetuximab (tropisetron } \\
5 \mathrm{mg} \text { or ondansetron 4-8 mg, } 1 \text { amp } \\
\text { Dekort, } 1 \text { amp Systral) }\end{array}$} & Irinotecan (200mg) & 90 min infusion in 250 cc SS & + & + & & & \\
\hline & $\begin{array}{l}\text { Cetuximab (begining } \\
700 \mathrm{mg} \text {, maintenance } \\
500 \mathrm{mg} \text { ) }\end{array}$ & 120 min i.v. infusion & + & + & + & & \\
\hline
\end{tabular}

Table II. Protocols of treatments 2 
[17]. Although, there are studies for calculating cost of specific cancer treatments (breast cancer, lung cancer) in Turkey [18,19], there is not any published analysis for calculating cost of colon cancer. The aim of our study is to calculate the cost of colon cancer treatment protocols and cost per year with different combinations of protocols for Turkey using survival data calculated from a previously published Markov Model [16].

\section{METHODS}

Gazi University Hospital, which is the one of third treatment hospitals in Ankara, Turkey, treatment protocols for colon cancer treatment were used. Cost of FUFA ( 5 FU/LV), FOLFIRI, FOLFOX, bevacizumab/FUFA, bevacizumab/FOLFIRI, bevacizumab/FOLFOX, irinotecan and irinotekan/cetixumab protocols were calculated (Table I and Table II).

The costs were based upon average government reimbursement sales prices for a 70 $\mathrm{kg}$ patient with body surface area of $1.7 \mathrm{~m}^{2}$. Only drug and hospital base applications costs, like physician visit, intravenous drug infusion, etc, were included. The cost of pharmaceuticals and medical treatment used in the protocols were taken from the Social Security Institution's web site [20] (http://www.sgk. gov.tr) (Table III and Table IV). The cost of best supportive care was excluded.

Wong et al. developed a Markov model to estimate the cost effectiveness of up to three lines of therapy for metastatic colorectalcancer [16]. In this model, patients received one, two or three lines of therapy. In this model the "base case" scenario was single agent $5 \mathrm{FU}$. We used the estimated time on each line of therapy to populate this model. The median period of each protocol administered in combinations and life expectancy data

\begin{tabular}{lcc}
\hline \multicolumn{1}{c}{ Drug } & Package & Average price (US\$) \\
\hline 5-Fluorouracil & $500 \mathrm{mg}$ & $2.93(2.71-3.12)$ \\
& $1000 \mathrm{mg}$ & $5.50(5.34-5.82)$ \\
Bevacizumab & $100 \mathrm{mg}$ & 307.12 \\
& $400 \mathrm{mg}$ & $1,140.55$ \\
Cetuximab & $100 \mathrm{mg}$ & 276 \\
& $500 \mathrm{mg}$ & $1,533.33$ \\
Folinic acid & $40 \mathrm{mg}$ & $0.67(0.56-0.76)$ \\
Irinotecan & $40 \mathrm{mg}$ & 58.36 \\
& $100 \mathrm{mg}$ & 135.66 \\
\hline
\end{tabular}

Table III. Cost of drugs

\begin{tabular}{lc}
\hline \multicolumn{1}{c}{ Medical treatment } & Average Price (US\$) \\
\hline 1 amp Metpamid & 0.51 \\
1 amp Decort (8 mg) & 1.18 \\
1 amp Systral & 0.23 \\
SS 100 cc & 1.88 \\
SS 250 cc & 2.18 \\
Granisetron 3 mg amp & 23.70 \\
Tropisetron 5 mg & 17.39 \\
Ondansetron 4-8 mg & 3.32 \\
Loperamid tablet & 0.05 \\
1000 cc SF & 3.20 \\
250 cc \%5 dextrose & 71.12 \\
1000 cc \%5 dextrose & 17.39 \\
Multiple chemotherapy infusion & 34.66 \\
Mono infusion chemotherapy & 28.00 \\
Bed for out patient & 4.00 \\
Physician visit & 17.33 \\
Laboratories & 12.00 \\
\hline
\end{tabular}

Table IV. Cost of other medical treatment

*Average of the cost of granisetron, tropisetron, ondansetron $=$ US $\$ 14.80$

\begin{tabular}{lcccccc}
\hline & \multicolumn{2}{c}{ Combination of protocols } & Fourth line & LE & $\begin{array}{c}\text { Total cost } \\
\text { (weeks) }\end{array}$ & $\begin{array}{c}\text { Cost per } \\
\text { (US\$) }\end{array}$ \\
\hline \multicolumn{1}{c}{ First line } & Second line & Third line & (US) \\
\hline FUVA & Supportive care & - & - & 54.7 & 5,359 & 98 \\
FOLFOX & Supportive care & - & - & 70 & 16,553 & 236 \\
FOLFIRI & FOLFOX & Supportive care & - & 84.4 & 14,144 & 167 \\
FOLFOX and bevacizumab & Irinotecan & Supportive care & - & 95.1 & 63,288 & 665 \\
FOLFOX & Irinotecan & Irinotecan/cetuximab & Supportive care & 104.7 & 113,392 & 1,083 \\
FOLFIRI and bevacizumab & FOLFOX & Cetuximab & Supportive care & 113.8 & 135,020 & 1,186 \\
FOLFOX and bevacizumab & Irinotecan & Cetuximab & Supportive care & 111.9 & 156,858 & 1,401 \\
FOLFIRI and bevacizumab & FOLFOX & Cetuximab/irinotecan & Supportive care & 118.3 & 151,170 & 1,277 \\
FOLFOX and bevacizumab & Irinotecan & Cetuximab/irinotecan & Supportive care & 116.7 & 165,052 & 1,414 \\
\hline
\end{tabular}

Table V. Cost of combination of protocols

FOLFIRI = combined 5-FU, LV, and irinotecan; FOLFOX = combined 5-FU, LV, and oxaliplatin; FUVA = 5-fluouracil/leucovorin (LV); $\mathrm{LE}=$ life expectancy 


\begin{tabular}{|c|c|c|c|c|c|}
\hline & $\begin{array}{l}\text { Total cost } \\
\text { (US\$) }\end{array}$ & Life expectancy & $\begin{array}{l}\text { Incremental } \\
\text { cost (US\$) }\end{array}$ & $\begin{array}{l}\text { Incremental } \\
\text { life expectancy }\end{array}$ & $\begin{array}{c}\text { ICER } \\
\text { (US\$/LE) }\end{array}$ \\
\hline FUVA (5FU/LV) & 5,359 & 1.05 year ( 54.7 weeks) & - & - & - \\
\hline FOLFIRI then FOLFOX & 14,144 & 1.62 year (84.4 weeks) & 8,785 & 0.57 & 15,412 \\
\hline FOLFOX & 16,553 & 1.34 year (70 years) & Dominated & Dominated & Dominated \\
\hline FOLFOX/bevacizumab then irinotecan & 63,288 & 1.82 year (95.1 weeks) & 49,144 & 0.2 & 245,720 \\
\hline $\begin{array}{l}\text { FOLFOX then irinotecan then } \\
\text { irinotecan/cetuximab }\end{array}$ & 113,392 & 2.01 years (104.7 weeks) & 50,104 & 0.19 & 263,705 \\
\hline $\begin{array}{l}\text { FOLFIRI/bevacizumab then FOLFOX } \\
\text { then cetuximab }\end{array}$ & 135,020 & 2.18 years (113.8 weeks) & 21,628 & 0.17 & 127,223 \\
\hline $\begin{array}{l}\text { FOLFIRI/bevacizumab then FOLFOX } \\
\text { then cetuximab/irinotecan }\end{array}$ & 151,170 & 2.27 years (118.3 weeks) & 16,150 & 0.09 & 179,444 \\
\hline $\begin{array}{l}\text { FOLFOX/bevacizumab then irinotecan } \\
\text { then cetuximab }\end{array}$ & 156,858 & 2.15 years ( 111.9 weeks) & Dominated & Dominated & Dominated \\
\hline $\begin{array}{l}\text { FOLFOX/bevacizumab then irinotecan } \\
\text { then cetuximab/irinotecan }\end{array}$ & 165,052 & 2.24 years (116.7 weeks) & Dominated & Dominated & Dominated \\
\hline
\end{tabular}

Table VI. Incremental cost-effectiveness analysis of combination of treatment protocols

were taken from the published analysis. Cost of combination of protocols were calculated depending of these. Only cost of drugs were used for the calculations as in Wong`s study [16]. The analysis was conducted in the perspective of a third-party payer like the Turkish Social Security Institution which covers the $85 \%$ of the population. The exchange rate was US\$ 1 for TL 1.5. Incremental cost effectiveness ratio (ICER) was calculated for each treatment. Life expectancy was calculated to years from weeks for ICER. The threshold for ICER was taken from WHO [21].

\section{RESULTS}

The lowest cost for one cycle/month was established by FUFA (US\$ 342). It was fol- lowed by FOLFIRI (US\$ 390), irinotekan (US\$ 619), FOLFOX (US\$ 704), bevacizumab/FUFA (US\$ 2,730), bevacizumab/ FOLFOX (US\$ 4,367), bevacizumab/FOLFIRI (US\$ 5,203) and irinotecan/cetixumab (US\$ 11,625). Depending on the life expectancy the lowest total cost was established by FUVA (US\$ 5,359). It was followed by FOLFIRI then FOLFOX and FOLFOX, US\$ 14,144 and US\$16,553, respectively. The lowest cost for each week of life expectancy was established by FUVA with US\$ 98 (Table V).

Incremental cost effectiveness ratio (ICER) was calculated depending on life expectancies of each combination. Life expectancies were taken in year for ICER. FOLFOX,

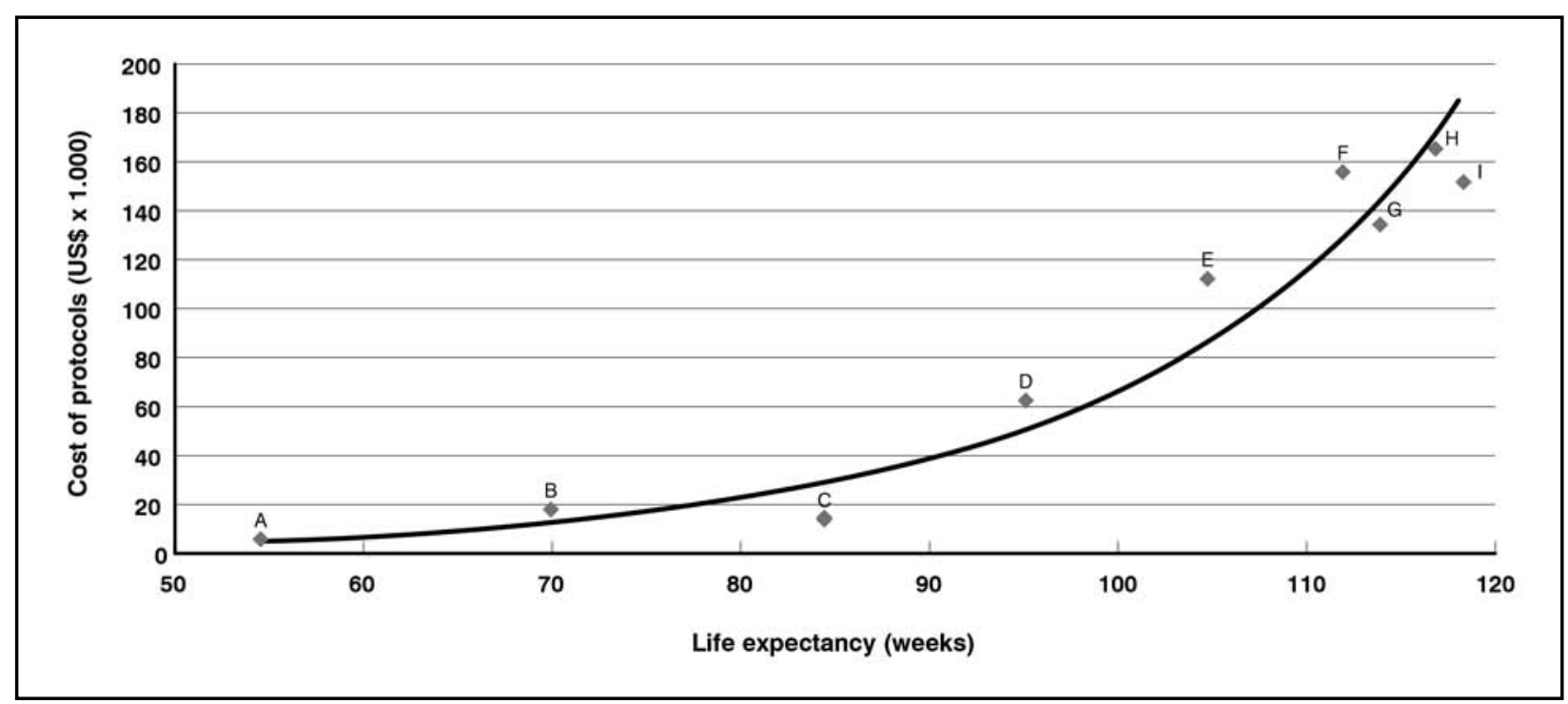

Figure 1. Cost-effectiveness curve of colon cancer treatments

$\mathrm{A}=$ FUFA; $\mathrm{B}=$ FOLFOX; $\mathrm{C}=\mathrm{FOLFIRI}$ then FOLFOX: $\mathrm{D}=$ FOLFOX/bevacizumab then irinotecan; $\mathrm{E}=\mathrm{FOLFOX}$ then irinotecan then irinotecan/ cetuximab; $F=F O L F O X /$ bevacizumab then irinotecan then cetuximab; $G=F O L F I R I /$ bevacizumab then FOLFOX then cetuximab; $H=F O L F O X /$ bevacizumab then irinotecan then cetuximab/irinotecan; I = FOLFIRI/bevacizumab then FOLFOX then cetuximab/irinotecan 
FOLFOX/bevacizumab then irinotecan then cetuximab and FOLFOX/bevacizumab then irinotecan then cetuximab/irinotecan were dominated. In addition, ICER of each compared treatment per life expectancy year was higher the limits of cost effectiveness threshold for Turkey which was mentioned by WHO [21], except FOLFIRI then FOLFOX compared with FUVA (Table VI).

On the other hand, if we calculate the average weighted curve for metastatic colon cancer treatment's cost compared with life expectancy, FOLFOX, FOLFOX/ bevacizumab then irinotecan, FOLFIRI then FOLFOX, FOLFOX/bevacizumab then irinotecan then cetuximab are above the curve. The other combinations are below the curve (Figure 1).

\section{DISCUSSION AND CONCLUSIONS}

It has been estimated that there will be 8-9,000 new colon cancer patients every year in Turkey, and metastatic colon cancer will be developed in 2-3,000 of them. Due the high prevalence and cost of treatment of metastatic colon cancer, there may be a huge budget impact to Turkish health system. Turkish reimbursement decisions are given by the commissions in Social Security Institution (SGK). After Ministry of Health`s approve the license of pharmaceuticals, all pharmaceuticals needs to make application to SGK for reimbursement. However, they need to show their cost-effectiveness against to available treatment options in the market, most of companies perform analysis depending on their Phase III study in which mostly placebo used for comparing. However, although companies perform analysis for reimbursement application, few analyses is published in journals, congress, etc. There is not any published pharmacoeconomic analysis for the colon cancer treatment in Turkey. This analysis is the first for the literature.

Our analysis have some limitations. Treatment protocols are dependent on only one University Hospital. Using the treatment protocols from different centers may lead to more accurate calculations for Turkey. Life expectancy Markov were calculated before KRAS testing which was used to identify patients who would respond to cetuximab. Due this the life expectancy will be different now for the predicting patients who may respond. This is the major limitation for the analysis. It is needed to run a new Markov with KRAS testing. In addition, discount rate was excluded from the analysis. Because there will be a discount in Turkish price, exchange rate TL/ US may change in years.
A USA study [22] evaluated the cost per 6 months of different treatment regimens: FU/ LV daily for 5 days, monthly (US\$ 96), infusional FU/LV every 2 weeks (US\$ 352), capecitabine for 14 days, every 3 weeks (US\$ 11,648 ), irinotecan every 3 weeks (US\$ $30,100)$, irinotecan weekly for 4 weeks, every 6 weeks (US\$21,500), FOLFIRI every 2 weeks (US\$ 23,572), FOLFOX every 2 weeks (US\$ 29,989), bevacizumab (alone) every 2 weeks (US\$23,897), cetuximab monotherapy weekly (US\$ 52,131), and panitumumab (US\$ 44,720). findings are similar to our findings. New drugs are serving more costly treatment option with higher survival rates than the older drugs.

Only FUFA, FOLFIRI then FOLFIX, FOLFIRI/bevacizumab then FOLFOX then cetuximab, FOLFOX/bevacizumab then irinotecan then cetuximab/irinotecan and FOLFIRI/ bevacizumab then FOLFOX then cetuximab/ irinotecan were under the cost-effectiveness curve.

There is no set definition of cost-effective and this may vary from country to country. The World Health Organization noted that if the ICER is lower than gross domestic product per capita (GDPC) or between 1-3 x GDPC or higher than $3 \times$ GDPC, it is very cost-effective, cost-effective or not cost-effective, respectively [21]. In this report the cost-effectiveness threshold is US\$ 9,972 for Turkey region, which is consistent with the GDP of US\$ 10,000 per year. The cost-effectiveness can be considered from US\$ 9,972 to US\$29,915 for each life year gained or quality adjusted life year.

The other combinations of protocols were above the cost-effectiveness curve depending on life expectancy. In addition no treatments ICER was under the WHO's threshold for Turkey, except FOLFIRI then FOLFOX compared with FUVA. It is possible that if a formal cost-utility analysis was performed in Turkey, it would be very difficult to justify the current prices of pharmaceuticals and almost all high priced pharmaceuticals would not demonstrate enough value to be reimbursed like oncology, orphan, etc. On the other hand, cost-utility analysis would be of more use to demonstrate the value of oncology medicines. Even then, oncology medicines are being reimbursed in Turkey whether they can or cannot demonstrate value using cost-effectiveness analysis because it would not be acceptable if there were news in media such that some oncology patients died due to the fact that government did not reimburse oncology medicines. Because there is also a traditional way of thinking in Turkey, such as when 
it is a health issue, it is not well accepted by public to talk about costs and money, as maintaining health should be more important than money. So, nearly all oncology treatments are covered by reimbursement by the Social Security Institution. It can be said that it is hard to change the reimbursement decision about this disease due to the low survival rate of colon cancer and social pressure. Even, the cost of colon cancer treatment in the USA was reported as US\$ 141,160 for per patient [23], there is not any data for Turkey. In addition most of cost-effectiveness analysis include comparing two different treatments. Due these the analysis is unique for literature. Further analysis is needed to be performed depending on new clinical outcomes and cost data.

\section{REFERENCES}

1. Agency for Health Care Policy and Research. Colorectal cancer screening: technical review. Rockville : Agency for Health Care Policy and Research, 1998

2. WHO. Global cancer rates could increase by $50 \%$ to 15 million by 2020 . Available via URL: http://www.who.int/ mediacentre/releases/2003/pr27/en/print.html

3. Song X, Barber ZZB, Gregory C, et al. Cost of illness in patients with metastatic colorectal cancer. Journal of Medical Economics 2011; 4: 1-9

4. The American Cancer Society (ACS). Cancer facts \& figures, 2002. Available via URL: http://www.uhmsi.com/ docs/CancerFacts\&Figures2002.pdf

5. Ministry of Health, Labour and Welfare of Japan. Population survey report [in Japanese]. Tokyo: Ministry of Health, Labour and Welfare, 2006

6. Omura K. Advances in chemotherapy against advanced or metastatic colorectal cancer. Digestion 2008; 77(suppl 1): $13-22$

7. Türkiye Kanser İstatistikleri (Cancer Statistics of Turkey). Center for early diagnosis, screening and training for cancer

8. Benson A. Epidemiology, disease progression and economic burden of colorectal cancer. J Manag Care Pharm 2007; 1: S5-18

9. Fight colorectal: cost of cancer care expected to skyrocket in next decade. Available via URL: http://fightcolorectalcancer.org/policy_news/2011/01/cost_of_cancer_care_expected_to_skyrocket_in_next_decade

10. Starling N, Tilden D, White J, et al. Cost-effectiveness analysis of cetuximab/irinotecan vs active/best supportive care for the treatment of metastatic colorectal cancer patients who have failed previous chemotherapy treatment. British Journal of Cancer 2007; 96: 206-12; http://dx.doi.org/10.1038/sj.bjc.6603561

11. [No authors listed]. Meta-analysis of randomized trials testing the biochemical modulation of fluorouracil by methotrexate in metastatic colorectal cancer. Advanced Colorectal Cancer Meta-Analysis Project. J Clin Oncol 1994; 12: $960-9$

12. [No authors listed]. Efficacy of intravenous continuous infusion of fluorouracil compared with bolus administration in advanced colorectal cancer. Meta-analysis Group In Cancer. J Clin Oncol 1998; 16: 301-8

13. Cunningham D, Pyrhonen S, James RD, et al. Randomised trial of irinotecan plus supportive care versus supportive care alone after fluorouracil failure for patients with metastatic colorectal cancer. Lancet 1998; 352: 1413-8; http:// dx.doi.org/10.1016/S0140-6736(98)02309-5

14. Rothenberg ML, Oza AM, Bigelow RH, et al. Superiority of oxaliplatin and fluorouracil-leucovorin compared with either therapy alone in patients with progressive colorectal cancer after irinotecan and fluorouracil-leucovorin: interim results of a phase III trial. J Clin Oncol 2003; 21: 2059-69

15. Tournigand C, Andre T, Achille E, et al. FOLFIRI followed by FOLFOX6 or the reverse sequence in advanced colorectal cancer: a randomized GERCOR study. J Clin Oncol 2004; 22: 229-37; http://dx.doi.org/10.1200/ JCO.2004.05.113

16. Wong Y, Meropol NJ, Speier W, et al. Cost Implications of New Treatments for Advanced Colorectal Cancer. Cancer 2009; 115: 2081-91

17. Kockaya G, Wertheimer A. What are the top most costly diseases for USA? The alignment of burden of illness with prevention and screening expenditures. Health 2010; 2: 1174-8; http://dx.doi.org/10.4236/health.2010.210172 
18. Uslu R, Kapkac M, Karaca B, et al. Screening for metastasis in primary breast cancer patients having four or more axillary lymph node involvement: is it really necessary? J BUON 2010; 15: 561-7

19. Cakir Edis E, Karlikaya C. The cost of lung cancer in Turkey. Tuberk Toraks 2007; 55: 51-8

20. Republic of Turkey. Social Security Institution. Available via URL: http://www.sgk.gov.tr

21. WHO. CHOosing Interventions that are Cost Effective (WHO-CHOICE). Available via URL: http://www.who.int/ choice/costs/CER_thresholds/en/index.html

22. Meropol NJ, Schulman KA. Cost of cancer care: issues and implications. J Clin Oncol 2007; 25: 180-6

23. National Service Center for Environmental Publications. Cost of illness. Enviromental Protection Agency, 2007. Available via URL: http://www.epa.gov/opptintr/coi/pubs/II_7.pdf 